\title{
A Fine Grained Scintillating Optical Fiber Hodoscope for use
}

$$
\text { CONF }-801103--8
$$

\author{
at ISABELLE
}

S.R. Borenstein ${ }^{\text {a) }}$, R.B. Palmer and R.C. Strand

Physics Department, Brookhaven National Laboratory, Upton, New York 11973

preserited at the 1980 Nuclear Science Symposium

Orlando, Florida, November 5-7, 1980

\section{MASTER}

a) University Affiliation: York CoIlege, CUNY, N.Y., N.Y.

The submitted manuscript has been authored under contract DE-AC02-76CH00016 with the U.S. Department of Energy. Accordingly, the U.S. Government retains a nonexclusive, royalty-free license to publish or reproduce the published form of this contribution, or allow others to do so, for U.S. Government purposes.

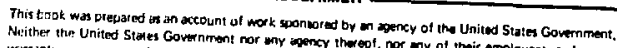

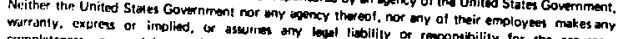

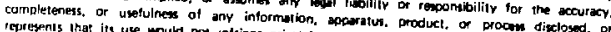

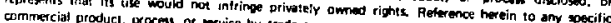

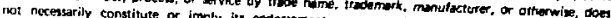

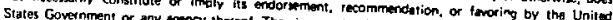

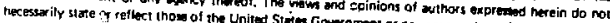


A FINE GRATNED SCINTILLATING OPTICAL FIBER HODOSCOPE FOR USE AT ISABELLE

\author{
S.R. Borenstein*, R.B. Palmer and R.C. Strand \\ Phyalcs Depertment \\ Brookhaven Netionel Leboratory \\ Upton, New York 11973
}

\title{
Ábetract
}

In order to exploit the high event rates at ISABELLS, It will be necesery to heve fast detection with Eine spatial resolution. The authors are currently constructing a prototype fine-gralned hodoscope, the eicments of which are scintillacing optical fibers. The Elbers have been drawn from comercially avallable plastic scintillator which hes bean clad with a thin layer of sificone. So far it has been demonstrated with one momet diamer fibers, that with a photodetector at ach end, the Eibers are wore than 997 efficient for lengths of about $60 \mathrm{~cm}$. The readout will be accomplfshed either with small diareter photomultiplier tubes or avalanche photodlodes used elther in the 11near or Galger mode. The program of fiber development and evaluation will be described. In addition an account of the progzess on the prototype hodoscope will je ziven.

\section{Incroduction}

When ISABELLE, the colliding beam accelerator, comes on line with a luminostey of $2 \times 10^{32} \mathrm{~cm}^{-2} \mathrm{sec}^{-1}$, there will be about $10^{7}$ pp Interactions per second with an average mult 1plicity of about 20 . Betweep $5.7^{\circ}$ and $45^{\circ}$, about 80 this $s r^{-1}$ is the expected rate. 1 To exploit this high rate, fast high resolution detectors rade from scintillating optical fibers have been developed. Early attempts ${ }^{2}$ to produce long bare scintillating filements of one ma diameter yielded maximum useful lengths of about $15 \mathrm{~cm}$, presumaly due to cummulative losses at the scintiliator to air interface. ${ }^{3}$ In order to Increase the useful length of the scintillating fiber the experience and expertise of the fiber optics Industry ws used to draw a Elber from a heated preform of polished PVT scintillator, and to coat this with a cladding of lower refractive index. The princ1ple is fllustrated in Figure 1 where those rays of igint making an angle, relative to the flber axis, of less than the numerical aperture angle of the fiber are trapped and guided to the end of the fiber where they are detected by a phocodetector. A desirable candidate for the phocodetector is the avalanche piotodiode (APD) which has the virtue of smill size and immity from angnetic flalds. It has a photon to electron quantum afficlency about 4 times zreater than that of a photoaultiplier tube; however, the probability that the photoelectron will propagate to a usable gignal is correspondingly lower. Thus the sensitivity of the APD is comparable to that of the PMT.

\section{Hodoscope Descr1ption}

A section of a hodoscope constructed from such scirtillating fibers is shown schematically as a b1layer of fibers tmbedied in a protective isolating matrix. The centers of the Efber 3 are of $f$ set by one adius frow one layer to the next to assure that there are no cracks through which a particle might pass withouc penerracing a reasonable depth or scintiliator.

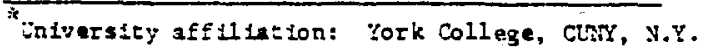

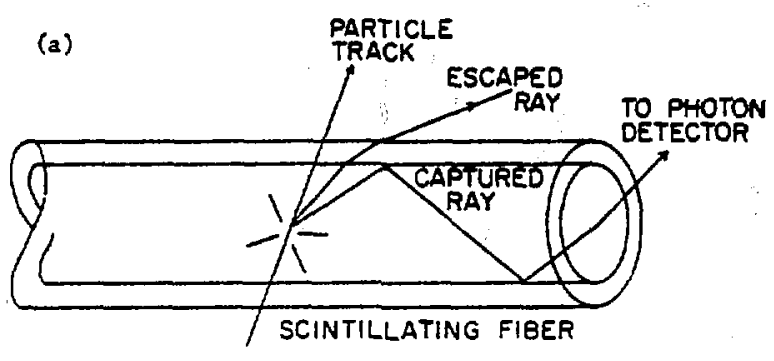

(b)

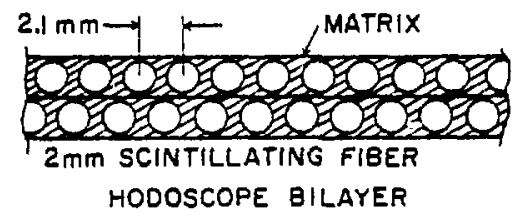

Figure 1 (a) Scintillating optical fiber, principle of operation; (b) Bilayer of fibers, encapsulated in 1solating matrix.

\section{Eiber Evaluaclon Procedure}

\section{Experimental Setup}

In order to establish the Eeasibil ity of such a bodoscope, Brookhaven Nacional Laboratory entered into a contract with Galtleo Electro-optical Corporation to undertake an experimental progran to draw and clad scintillating fibers. Varlous comerctally avilable scintillators, several cladding matertals, curing methods, temperatures, tenslons, and draw speeds were tried.

The scintillators NE102, NE11O and NEJ61, were obtalned from Nuclear Enterprises. The cladding materinls have been a proprietary ultraviolet cured acrylic and a heat cured silicone. The best results to date have been obtained with silicone coated NEl 61. The layout of the test facility appears in Figure 2. An electron from Ruthenium 106 penetrates two small telescope counters $T_{1}$ and $T_{2}$ which sandwich the fiber. Upon a colrcidence from $T_{1} T_{2}^{2}$, the signal from $S 1$ is detected by an $R C A 8850$ photomuleiplier with single photoeiecton resolution. From the resultant spectrum in Figure 2 me can calculate the mean number of piotoelectrons ( 4 in the example shown).

\section{Test Results}

The highlights of the results obtained so sar are 


\section{CHARGE SPECTRA OF SCINTILLATING FIBER USING RCA 8850 PHOTOMULTIPLIER}

(a)

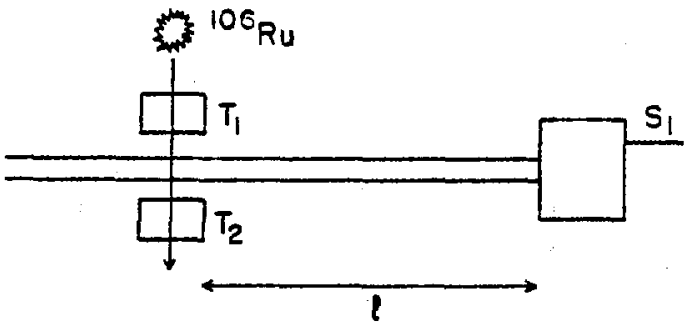

(b)

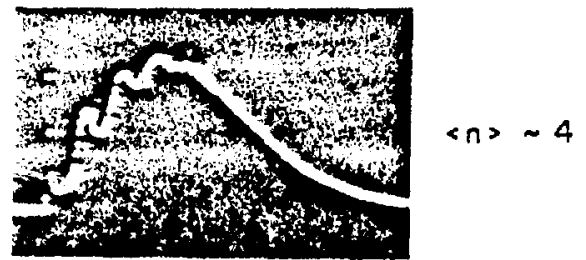

Figure 2 (a) Fiber measurenent setup: electron from source penetrates scintillators $T_{1}$ and $T_{2}$ as well as the $f$ iber whose output signal $S I^{2}$ is analyzed; (b) Charge spectrum of fiber pulse using RCA 8850.

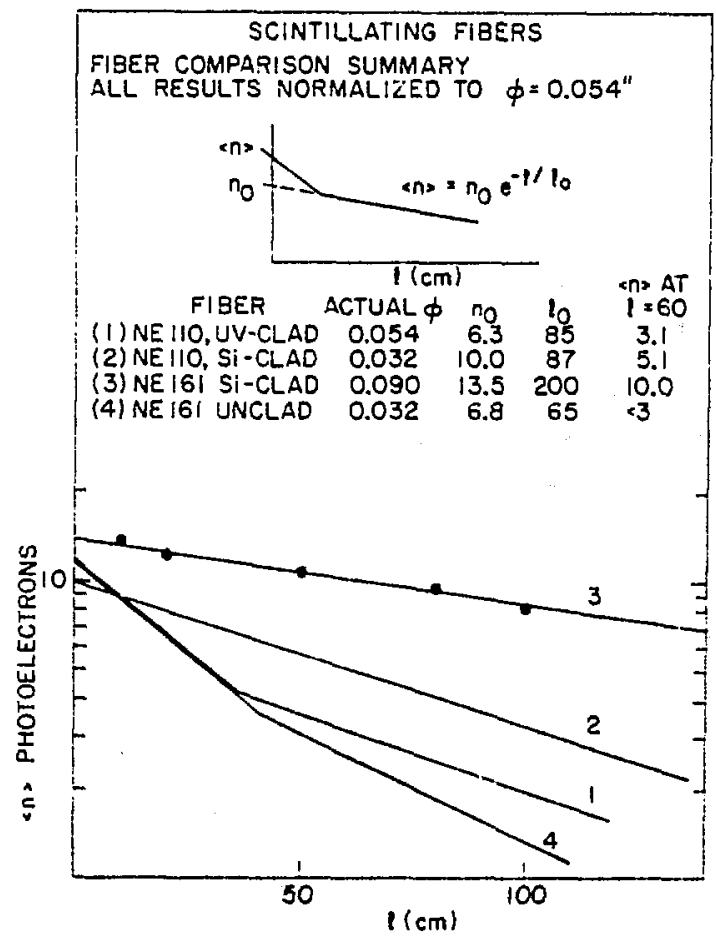

Flgure 3. Ateenuacion curves for various E1bers. shown in the curves of F18. 3, and in the acconpanying table where each flbor is characterized by en attenuaflon length and an effective photoelectron yield at the orisin. The data were obtained frov fibers whose diameter varied frow .032" to .090" but the resules have all been scaled to a dieneter of .054 " or 1.37 gin. The prograssion of curves 1 through 3 show a steady improvement due in part to choice of material, and in part to gradually improved tecinlque. Curve No. 4 underseores the drastic actenuation suffered at the scincillator to air surface. Thus, we have successiully produced scintillating flbers 1 tim in diameter of lengths approaching 1 weter, with detection efficlency approaching 100\%.

\section{Avalanche Photod tode Readout}

We are bullding a barrel hodoscope for use at CERN experiment ISR 807 in which a half cylinder of radius $18 \mathrm{~cm}$ will be fitced with $60 \mathrm{~cm} 10 \mathrm{ng}$ flbers of $2 \mathrm{~mm} \mathrm{dla}-$ meter to form a hodoscope with bout 500 readout channels. The photodet-ctor under development for readout is a cooled APD operated in the saturaced mode at about $-100^{\circ} \mathrm{C}$.

In this mode of operation with the APD Slased above che oreakdowi voltage, a phocoel ectron has a small (on the ordex of $20 \%$ ) probability of causing a breakdown signal. This probability is an increasing function of the overvoltage, but the signal size is independent of the number of photoelectrons that contributed to it so that the signal containg no analog information, and it oceurs with a probability which depends upon the overvoltage as well as the number of photoelectrons. On the other hand, there is a dynamic dark count proportional to the true counting rate, which also incresses with overvoltage. Thus, there is an optinun overvolcage obtained by trading off required photoelectron input versus acceptable dark count as shown in FIgure 4 winlch shows required photoelectron input versus overvoltage for a detection efficiency of $99.9 \%$. The other curve shows the total to input counting ratio as a function of the overvoltage, thus for an acceptable dynamic dark count of $20 \%$ the required ingut is 22 photoelectrons per pulse.

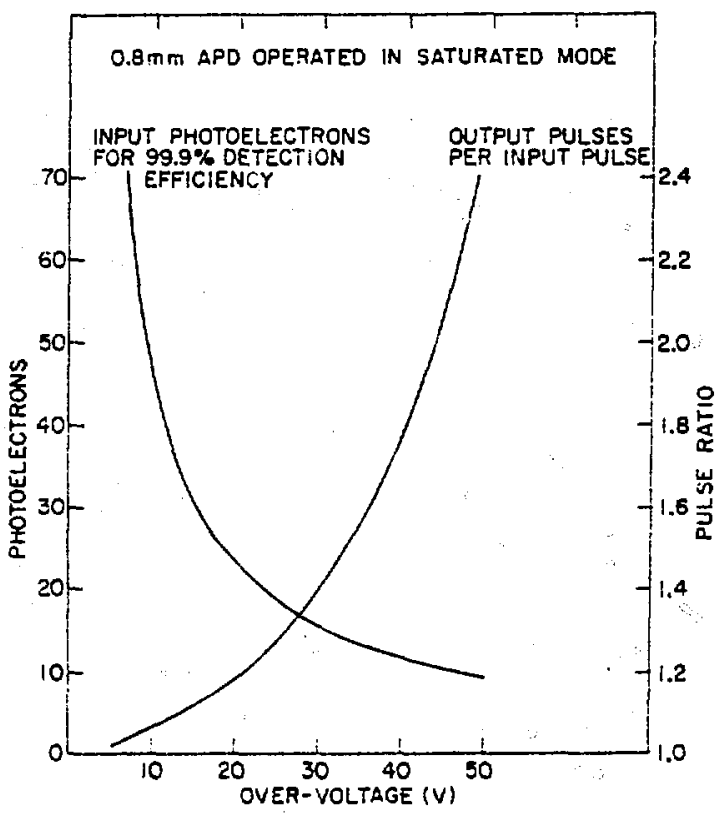

Figure 4. SPD operacion as a function ar vyervolcage. 
If we relix the officlency requirenent to $99 x$ the photoliectron requirement is reduced by $25 \%$. Sirilarly if we allow the dynumic dark count to increase to $30 \%$, the photodecion budget can be raduced by $25 \%$. Referring beck to Eigure 3 , and acaling to 2 ma flbers of length $60 \mathrm{~cm}$, we $E$ ind the number of photoel ectrons would be about $15 \times 4$ (for the mperior quantum off1ciency of an APD) or 60 photoclectrons if the optical coupling from ftber to APD jere a good as from fiber to PMI. Because of the gmall size of the APD, and the need to interpose a lens between the fiber and the detector, the margin of safety will be smaller. We are presently optinizing the 1 ight coupling from fiber to detector.

\section{Conclusion}

Having dewonstrated the sensibility of the seincillating fiber as a flue grained hodoscope elenent, we are proceeding to bulld such an instrument while at the same time, continuing sith the program of improverent of fiber performance. To this and we do not expect to see any major improvement in seintillator light Yielc. He are not aware of a sultable cladding with a lower refractive index than the heat cured sllicone, so the effective pioton yield at the origin way not be increased nuch more. An inproverent in the bonding betreen cladding and core should extend the attenuation leng:h to approach that of the fulk sciatillator. It should also make the flbers wore rugged and resistant to deterforation as a result of handling. Thus, our Euture efforts will be concentrated upon improved bonding methods as well as upon hodoscope fabrication techs. Ique.

Th1s research was supported by the U.S. Department of Energy under contract to. DE-ACO2-76CH00016.

\section{References}

1. J. Warx and S. Ozak1, Toplc I: Detectors and Experiments, Summary of Activity, PFoc. 1977 ISABELIE Sunmer Norkshop, BNL 50721, p. 4 .

2. G.I. Reynolds and P.E. Condon, Rev. Sc1. Instr. 28, No. 12, Dec. 1957; G.T. Reynolds, Vucleonles 16, ₹o. 5 , June 1958 .

3. I. Reiffel and X.S. Kapany, Rev. Sc1. Instr. 31, $1136-1142(1960)$.

4. BNR Contract $\$ 463787-S$ with Galieo Electro-Optical Company.

5. S.R. Borenstein, R.3. Palmer and R.C. Strand, Optical Fibers and dvalanche Photodlodes for Scintillator Counters, presented at the International Conierence on Expertmentation at LEP, Uppsals, Sweden, 16-20 June, 1980. 